\title{
Healthcare system error: beyond apology
}

\section{David P Stevens}

When a healthcare professional commits an error that results in an adverse patient outcome, it is increasingly considered appropriate that an apology should be made to the harmed person. ${ }^{12}$ Such an apology benefits both the health professional and the patient, and serves to address the considerable emotional burden that accompanies this wrenching aspect of practice (see page 249). ${ }^{1}$ The process of apology invariably calls for candid self-reflection and, in the best of circumstances, leads to better and safer care. It emphasises that healthcare is at its heart a social process that contains predictable human emotions that contribute to its value but can also serve to facilitate its improvement.

\section{WHERE DOES APOLOGY FIT IN HEALTHCARE SYSTEMS?}

What, then, is appropriate when a system fails a patient? Is an apology due? To whom should it be addressed? Surely most would agree an apology is due the patient, particularly when the error is due to an identifiable mistake, such as a "Never Event," a term that has been used to identify the most egregious and preventable errors. $^{3}$ Typical examples of "Never Events" include wrong-side surgery, or falls in a healthcare facility. Moreover, the list grows as health systems, and those who finance care, find common cause in their elimination. ${ }^{3}$

But there are other stakeholders who are involved in health systems that may be worthy of an apology if the most is to be gained from such a distressing event. For example, what about the health professionals who work in such a system? Are they due an apology when they find themselves working in a health system that does not support professional performance at its highest potential and consistent with their professional aspirations?

Is a trainee who is learning in a teaching hospital where care is error-prone owed an apology? Does such an institution provide a substandard education if its

Correspondence to: Dr David P Stevens, Quality Literature Program, Dartmouth Institute for Health Policy and Clinical Care, 30 Lafayette Street, Lebanon, NH 03766, USA; david.p.stevens@dartmouth.edu education mission is not sufficiently focused to continuously strive for the highest standard of system performance? ${ }^{4}$

"Never events" are readily identifiable, but, what about a system's failure to comply with known processes for better, safer care? If, for example, there are relatively simple processes that are known to reduce infections in intensive care units, ${ }^{5}$ and they are not employed, where does the culpability lie? I would argue that such a healthcare system is blameworthy when such knowledge is at hand to avoid an adverse outcome. But for a healthcare system, there is more to this than apology if such events are to be prevented in the future.

\section{BEYOND APOLOGY: THE ROLES OF SENSEMAKING AND LEADERSHIP}

A health system defect that goes undetected reflects the absence of what Weick has called "sensemaking," which is essential if corrective action is to be implemented. ${ }^{6}$ Fortunately, examples abound of just such "sensing" systems, and these examples point directly to the role of profoundly committed leadership. When Cincinnati Children's Hospital recognised that outcomes in their patients with cystic fibrosis were just average when compared with outcomes of similar institutions throughout the US, the leadership in Cincinnati acknowledged this to the parents of these children because they recognised there was knowledge that would enable them to perform better. And arguably more importantly-they linked that apology to an invitation to patients to participate in improvement teams. $^{78}$ When the leadership of the University of Missouri-Columbia hospital recognised that system defects could be the underlying cause of mishaps, they redesigned weekly morbidity and mortality conferences to pursue root cause analyses of such mishaps. 9 They progressed from the traditional culture of blame that permeates traditional morbidity and mortality conferences to acknowledgement of the need for system improvement-for the benefit of both patients and health professionals. They formed ad hoc improvement teams that were made up of professional staff including resident trainees that were crafted to improve the system defects.

Recognition of a system defect-particularly one that continues to put patients unnecessarily at risk-certainly calls for apology. But there is more. If improvement does not follow, what has been accomplished beyond this important acknowledgement at a personal level? I suggest it calls for a culture of professional impatience that strives for continuous improvement that inevitably requires effective corrective action. Moreover, the institution's senior leadership owes the staff responsiveness to this impatience. Bate and colleagues go beyond this in their description of a case study of the Reiner de Graf Groep hospital system in The Netherlands ${ }^{10}$ where they emphasised that this calls for what they call effective "distributed leadership" that extends from the governance board through the chief executive and down to individual unit leadership. Such distributed leadership is intolerant of anything less than continuous attention to healthcare quality and patient safety.

\section{COLLECTIVE CONTRITION AND BETTER, SAFER CARE}

Perhaps this is not apology in the formal sense, but in examples such as Cincinnati Children's, University of Missouri and Reiner de Graf Groep described above, what I would call collective contrition for system failure relentlessly proceeds to corrective action. This results in continuously improving care for patients, a values-driven professional environment for clinicians, and the best possible setting for students and trainees to form habits for a career in which healthcare is continuously improved. ${ }^{11}$ Without relentless commitment to healthcare improvement and safer patient care at the system level, apology alone proves hollow.

\section{Competing interests: None.}

Accepted 2 July 2008

Qual Saf Health Care 2008;17:234-235.

doi:10.1136/qshc.2008.029595

\section{REFERENCES}

1. Van Pelt F. Peer support: healthcare professionals supporting each other after an adverse event. Qual Saf Health Care 2008;17:249-52.

2. Lazare A. On apology. New York: Oxford University Press, 2004:306.

3. CMS Office of Public Affairs. Eliminating serious, preventable, and costly medical errors - never events. http://www.cms.hhs.gov/apps/media/press/ release.asp?Counter $=1863$ (accessed 3 July 2008) 
4. Seiden SC, Galvan C, Lamm R. Role of medical students in preventing patient harm and enhancing patient safety. Oual Saf Health Care 2006;15:27-76.

5. Pronovost $\mathbf{P}$, Needham D, Berenholz S, et al. An intervention to decrease catheter-related bloodstream infections in the ICU. N Eng J Med 2006;355:2725-32.

6. Weick KE. Sensemaking in organizations. London: Sage, 1995:231.
7. Reinertsen JL. Interview with James M Anderson, Chief Executive Officer, Cincinnat Children's Hospital Medical Center. Oual Saf Health Care 2006:15:443-4.

8. Gawande A. The bell curve. The New Yorker 6 December 2004.

9. Bechtold MK, Scott S, Nelson K, et al. Educational quality improvement report: outcomes from a revised morbidity and mortality format that emphasized patient safety. Qual Saf Health Care 2007; 16:422-7

10. Bate $\mathbf{P}$, Mendel P, Robert G. Organizing for quality Oxford: Radcliffe Publishing, 2008:83-100.

11. Batalden PB, Davidoff F. What is "quality improvement" and how can it transform health care. Qual Saf Health Care 2007;16:2-3.

\section{Abstracts}

\section{Presentation abstracts from the International Forum on Quality and Safety, April 2008, Paris, France}

This issue of OSHC is accompanied by an online Supplement where abstracts are published from the International Forum on Quality and Safety in Health Care that took place in Paris in April 2008. The abstracts that were commissioned for this Supplement were originally selected by reviewers for oral presentations in Paris.

The over 900 abstracts that were submitted for the 2008 Forum reflect an extraordinary commitment to health care quality and patient safety. They represent improvement work from over 20 countries. These currently published abstracts, along with those that were linked to the 376 posters that were presented at the Paris Forum, emerged from a rigorous peer-review process.

The criteria for their selection reflected the consensus of reviewers and included clear aims, attention to explicitly defined methods, and accurate measurement of outcomes. Good improvement work invariably offers new lessons for better, safer care, and insightful analysis of these projects for lessons learnt was an important part of the successful reports. Finally, mindfulness of how the work might be adapted from these specific settings to other contexts of care is a vital part of effectively reporting good work so that it might contribute to wider opportunities for health care improvement and patient safety.

The Editors of OSHC congratulate the authors of these valuable reports, and look forward to the improvement work that will be reported at the International Forum in Berlin in March 2009.

\section{David P Stevens \\ Editor-in-Chief}

Correspondence to: Dr David P Stevens, Quality Literature Program, Dartmouth Institute for Health Policy and Clinical Care, 30 Lafayette Street, Lebanon, NH 03766, USA; david.p.stevens@dartmouth.edu

Qual Saf Health Care 2008;17:235. doi:10.1136/qshc.2008.029603 